\title{
O MODELO DA NATUREZA E A NATUREZA DO MODELO
}

\author{
Ana Godoy \\ Cientista social, Pesquisadora bolsista da Fapesp
}

\begin{abstract}
Resumo: Este artigo aborda as diferentes articulações entre os processos que permitem e validam a criação de áreas protegidas, segundo um modelo que tem como fundamento a existência de uma única natureza. Tal abordagem permite explicitar os percursos inventados pela ecologia na constituição de um território científico e os critérios que esta área de conhecimento cria e estabelece no esforço de definir a Natureza e aquilo que nela deve ser considerado como "destinado a preservação".

Palavras-chave: ecologia; áreas de proteção; conservação.
\end{abstract}

\begin{abstract}
O que é a vida? Não sei. Onde é que ela habita?
Ao inventar o lugar, os seres vivos respondem a esta questão. Michel Serres, Atlas
\end{abstract}

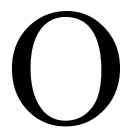

objetivo deste artigo é propor um exercício criativo de pensamento, no qual as áreas de proteção serão colocadas em jogo, menos para explicálas do que para pô-las a prova na sua relação com outros elementos e outras idéias, de tal maneira que, ao fazê-lo, o que se pretende é criar um campo de problematização. Desse modo, a abordagem da questão das Unidades de Conservação no Brasil será feita a partir da recusa do senso comum que, via de regra, explicita-se sob a forma de práticas mais ou menos ecológicas, no drama do fim da natureza ou na falência da vida sobre a Terra, e ainda no reconhecimento da criação de áreas protegidas como um possível antídoto "para estados de coisas degenerados".

O debate em torno da criação de áreas de proteção remete diretamente à idéia de um modelo, que explica os objetivos das áreas e suas formas de uso, assim como reprime a invenção de um conceito de natureza, sua relação com diferentes coletivos e indivíduos e a sua importância dentro do espaço sociocultural configurado ao longo de seu processo de construção.

No Brasil, como também no restante da América Latina, África e Ásia, associa-se o modelo de Unidades de Conservação àquele desenvolvido pelos Estados Unidos a partir da criação do Parque Nacional de Yellowstone em 1872. Esse parque corresponde não só a um marco da preservação de áreas silvestres de grande escala e do interesse público mas, principalmente, estabelece os fundamentos do chamado modelo de Unidades de Conservação: a proteção de amplos espaços naturais, de grandes belezas cênicas capazes de assegurar a continuidade dos processos biológicos sem interferência humana.

Nesse caso, mesmo considerando-se que a formulação e sistematização da proposição de um modelo de áreas protegidas, fundamentado num conceito de natureza, não tenha se dado independentemente das singularidades criadas no processo de colonização do continente norte-americano, as quais dizem respeito simultaneamente à invenção de um território e de um povo, de uma natureza e de uma cultura, ainda assim a idéia de um modelo está presente e se torna senso comum da ecologia.

A partir daí, a pergunta que se coloca é: O que acontece quando se diz que alguma coisa é modelo? O que acontece quando se diz que Yellowstone é um modelo?

Não se trata mais de afirmar que o Parque Nacional de Yellowstone é um modelo ou que as áreas existentes em outros países tenham sido criadas com base nele, mas sim de acoplar o modelo ao ato de formar uma natureza que constitui, por sua vez, coletivos e indivíduos humanos e não-humanos, uma cultura, uma tradição; um âmbito que, ao tornar válido o modelo, permite sua conservação e de 
toda a rede de interações ao qual está articulado e com o qual é configurado. Ou seja, não vem ao caso considerar que o modelo esteja errado ou que o fracasso ou o sucesso das áreas implantadas possa ser determinado por ele, mas de rearticulá-lo à sua própria história de criação, desnaturalizando os conceitos que o formam, eliminando qualquer possibilidade de explicar o modelo ou as áreas criadas a partir de uma natureza dada a priori.

O funcionamento das redes de interação, portanto, na qual o modelo é criado, constitui o problema, pois definir a natureza que se quer preservar significa, em última análise, preservar a rede da qual ela emerge.

O que se pode afirmar com isso é que a experiência da natureza - e a totalidade de signos a ela relacionados - é transformada pelas singularidades estéticas, conceituais e funcionais co-determinadas pela singularidade das experiências vividas. Nesse processo configura-se uma rede de interações, na qual todos os elementos que a compõem estão em permanente movimento, deslocando-se de um domínio a outro, estabelecendo novas ligações cujas significâncias estão sempre referidas na própria rede em que são produzidas.

É a invenção constante de relações sempre inéditas entre o território e os corpos que o atravessam que produz aquelas construções culturalmente compartilhadas, ensinadas e apreendidas, que motivam a ação, transformam o humano e o natural em que são configuradas, relações essas transformadas todo o tempo. Para entender o funcionamento de tais redes é necessário seguir o emaranhado das linhas, de um domínio a outro, atravessando mundos, diferentes naturezas. Uma viagem tão fascinante quanto perigosa, pois os caminhos só se revelam à medida que os seguimos.

\section{YOSEMITE E YELLOWSTONE: DESNATURALIZANDO O MODELO E REVELANDO AS REDES}

O Parque Estadual de Yosemite (1864), criado no auge da Renascença americana, protegia e enaltecia a sublime e profunda beleza natural, preservando o instante preciso da criação divina. ${ }^{1}$ Ele possibilitava aos homens da América entrar em contato não só com o conjunto perfeito e harmonioso da obra de Deus mas, principalmente, poder ali reconhecer a grandiosidade do destino reservado à América e aos americanos.

A criação de Yosemite realizava concretamente a crença no enraizamento do homem norte-americano na natureza, pela qual Deus tornava manifesto o destino desse homem no Novo Mundo. ${ }^{2}$ Yosemite era o reconhecimento de sua superioridade moral e o substrato da nação que emergia. A partir de sua criação abria-se a fronteira em direção ao Oeste.

Seus altos cumes e profundos vales encravados em meio às áreas de mineração, longe de se contrapor, afirmavam a capacidade desse homem em cultivar a terra inculta e assim criar uma cultura a partir da natureza, reconhecendo nela a sua tradição. ${ }^{3}$

O Parque Nacional de Yellowstone (1874), por sua vez, foi criado no período que corresponde ao declínio da Renascença americana e ao nascimento de um pensamento e de uma sociedade fundados no pragmatismo científico e filosófico. ${ }^{4}$ No entanto, mesmo surgindo em momentos diferentes, os valores incorporados nessas áreas estavam profundamente relacionados ao complexo movimento de invenção da América e do homem americano.

É em Yellowstone que se articula, pela primeira vez, uma resposta estética e científica sobre a natureza. ${ }^{5} \mathrm{Na}$ sua criação estava implícito um conjunto muito amplo de saberes de técnicas e tecnologias - desconhecidos na época da criação de Yosemite. No entanto, em nenhum momento isso significou o abandono das concepções anteriormente estabelecidas. Ao contrário, Yellowstone parecia melhor acomodar o racionalismo de Jefferson, o teísmo de Edwards e o transcendentalismo de Emerson, compondo um amálgama que perpassava a explicação científica.

Criado no período que corresponde à queda da última fronteira, Yellowstone revelava a amplitude dos propósitos divinos compondo pela primeira vez uma totalidade que se identificava com a nação. Ali se enredavam a variedade da natureza, a riqueza mineral e a beleza natural, cuja existência vinculava-se à existência dos homens no território.

Observa-se que à criação dessas áreas correspondeu não só a invenção de uma natureza, mas também a invenção dos domínios explicativos capazes de descrevê-la e, neste processo, colocá-la em movimento. Conectando os mais diversos elementos, jogando-os de um domínio a outro forma-se uma rede na qual as linhas e os itinerários se sobrepõem e as áreas de proteção correspondem aos pontos de fundação, de enraizamento de uma cultura.

A idéia de preservar áreas em proveito das populações urbanas, ou ainda a idéia de protegê-las do avanço da civilização, só adquire forma - passando a fazer parte, então, do conceito de áreas protegidas - no início do século $\mathrm{XX}$, quando o "projeto de terra livre" é definitivamente abandonado. ${ }^{6}$ 
No período entre 1830 e 1870 a idéia de preservação/ conservação, ela mesma um emaranhado de significações, remete e é remetida aos diferentes espaços do saber, fazendo ecoar, até os dias de hoje, a polêmica em que se procurava definir o que era a natureza norte-americana e qual era a natureza do homem que lá vivia. Revela-se assim o percurso elaborado na tentativa de configurar uma natureza possível de ser compartilhada pela sociedade norte-americana, pois no ato de descrever tais naturezas sempre estava presente a seleção daquela, ou daquelas naturezas, que se apresentava como mais viável ou efetiva na conservação de um conjunto de condutas - valores, crenças, sentimentos, idéias - em constante mutação.

É dentro desse quadro que a criação de Yosemite e Yellowstone só pode ser pensada como sendo indissociável da própria experiência do homem norte-americano, de sua história e de suas tradições.

Percebido e tomado pelos filósofos, pintores e cientistas - mas também pelos políticos e pelos homens e mulheres comuns, como coloca Whitman -, esse processo ganhou uma potência de diferenciação, surgindo em cada dimensão da vida norte-americana, constituindo um corpo teórico capaz de explicar e justificar todas as ações. Um processo em que se inventa uma filosofia, uma ciência, uma arte, enfim pontos de vista indissociáveis da experiência norte-americana de deslocamento e fragmentação territorial, de vastidão e solidão.?

Tanto Yosemite quanto Yellowstone eram o presente que passava e, ao mesmo tempo, a conservação de um passado que se criava numa concepção fortemente a-histórica. Estabelecia-se uma origem, a sua origem, num presente constantemente reinventado. Seus fundamentos eram os mesmos e seus objetivos convergiam para uma mesma direção: a invenção de um território político, a afirmação da grandiosidade e da riqueza moral do homem, comparáveis somente à grandiosidade e à riqueza do continente que a ele havia sido destinado.

Assim, a natureza descrita em Yosemite, primitiva, original, fonte primeira do belo, do verdadeiro, permanecia viva em Yellowstone.

É nesse processo que o surgimento da ciência ecológica, enquanto ciência aplicada, reconfigura Yellowstone, transformando a área não em um modelo, mas em uma matriz capaz de gerar modelos teoricamente aptos a cumprir os objetivos, fossem eles de conservação ou de preservação, transformando a natureza em algo possível de ser objetivado e, portanto, explicado como natureza-função.

\section{CRIANDO LUGARES}

A criação de áreas protegidas com a finalidade de proteção de recursos tem sido compartilhada por diferentes culturas. No entanto, o caráter prescritivo das áreas, como territórios que somente alguns indivíduos teriam acesso, foi sendo mudado à medida que se transformavam os diferentes domínios de saber, alterando-se a distribuição dos elementos humanos e dos não-humanos, de tal forma que cada um ocupasse um lugar "próprio".

No entanto, permanece vívida a crença de que tais lugares são, de alguma forma, predeterminados - seja por Deus, pela natureza ou pela razão -, e sua existência é, antes de mais nada, independente das explicações que se procura dar. É esse o caminho que permite afirmar que aquilo que um coletivo de indivíduos compartilha é a natureza, algo a ser protegido ou perpetuado, e não sua experiência descritiva inscrita num determinado território.

Desde há muito tempo essa concepção tem contribuído para manter invisíveis, ou quando muito apresentar como paradoxais, todas as naturezas diferentes daquela que o coletivo reconhece como "a verdadeira natureza". Caberia a ela, em seu modo de operar, designar posições e estabelecer hierarquias, as quais só se modificarão a partir daquilo que a entidade - seja ela natureza, Deus, razão -, tornada autônoma, reconhecer como sendo dela, e o que não é "próprio" deve ser ajustado a ela ou simplesmente ignorado.

Nesse sentido, a potência das naturezas, descritas em sua singularidade e heterogeneidade, era - como ainda é - investida de significados políticos, econômicos e culturais para além do que hoje se chama biodiversidade, e as áreas protegidas, por sua vez, surgem como uma forma específica de pensar o espaço e de apropriar-se dele, a partir da criação de lugares.

Deixando de ser um espaço produzido e circunstanciado pelo deslocamento - caravanas de homens, ordas de animais, migração das aves, ventos e tempestades -, onde a experiência da natureza surge como uma relação com um mundo que se configurava no movimento, no cruzamento de percursos singulares, ele passa a ser descrito como o lugar da proteção.

Dessa forma, o caminho que leva na direção das Áreas Protegidas corresponde a uma lenta e progressiva transformação, na qual o espaço heterogêneo e instável - e nesse sentido, ameaçador - e as relações configuradas na descrição dessa experiência tornam-se lugar, uma ordem segundo a qual os elementos humanos e não-humanos po- 
dem ser distribuídos nas relações, de acordo com aquilo que lhes é "próprio" (Certeau, 1996:202).

A designação do que é "próprio" é, nessa perspectiva, a qualidade intrínseca da entidade à qual a explicação científica se remete. E o lugar é sempre alvo de uma permanente reordenação de posições determinadas pelas descobertas de novas regras científicas.

Permanece obscurecido por esse caminho que tanto as explicações quanto as descrições só possuem validade dentro do coletivo que as aceita e usa. Há, portanto, uma consensualidade necessária entre os membros de cada coletivo e dos diferentes coletivos, que torna possível que os critérios que validam as explicações sejam compartilhados.

Nessa abordagem, a criação de Áreas Protegidas se dá, concretamente, a partir da invenção de marcos que são distribuídos e reconhecidos nas relações estabelecidas entre diferentes indivíduos pertencentes a um mesmo ou a diferentes domínios de conhecimento, estabelecendo nesse movimento uma rede de interações.

Tais marcos são traduzidos por proteção, preservação ou conservação, e a possibilidade de serem compartilhados por um coletivo de indivíduos implica que correspondam às relações de significado estabelecidas por esses indivíduos dentro dos domínios descritivos configurados. Ou seja, pressupõe que sejam historicamente concatenados, uma vez que não existem fora da experiência daqueles que os descrevem. Sendo assim, diferentes domínios descritivos podem reconhecer, ou não, esses marcos de acordo com sua história de interações.

Nessa perspectiva, as Áreas Protegidas são lugares que adquirem especificidade a partir das operações que são feitas sobre eles, sendo que as Unidades de Conservação, por meio de uma minuciosa tipologização dos lugares, constituem tais operações que, por sua vez, são claramente explicitadas no discurso jurídico-científico, pois é nele que se dá a grande operação de demarcação.

\section{A CRIAÇÃO DE LUGARES COMO CONFIGURAÇÃO DE PROBLEMAS}

A criação de lugares e a definição das operações são lentamente fixadas no corpo do território, primeiro como uma prática, depois como procedimento, formando o âmbito em que a ecologia, pela biologia da conservação, surgirá como o domínio de conhecimento apto a estabelecer os modos de operação a partir dessas práticas já fixadas, isto é, o problema que se põe não é a destruição da natureza mas de como operar sobre ela.
Assim, as Unidades de Conservação, ao operar sobre os lugares, vinculam e desvinculam os indivíduos humanos e não-humanos, definindo territórios nos quais diferentes domínios explicativos irão compor ao mesmo tempo diferentes domínios de ações. Assim, devastar, explorar, proteger, emergem como marcos, como qualidades da experiência, que serão reconfiguradas a cada nova área criada.

Cada área criada atualiza a relação dos indivíduos e coletivos com uma natureza que se dá na própria criação das áreas. Ao mesmo tempo, cada área surge como um reservatório de possibilidades que serão ou não realizadas de acordo com sua potência de articulação. As áreas são tanto uma problematização a propósito da rede de interações onde elas se manifestam, quanto uma estabilização das relações posta em jogo dentro da rede. Assim, a potência de uma área se esgota quando ela não é mais capaz de articular a série aos coletivos e as tecnologias, deixando de ser efetiva, uma vez que os elementos articulados não permitem uma delimitação precisa do que deve estar dentro e do que deve permanecer fora dela.

Toda área sempre subsiste, levando sempre a novos arranjos, novas combinações de elementos para que se recomponham as relações dentro da rede em que foi inventada. Não se trata mais de florestas, de madeira ou de essenciais florestais, trata-se de corpos biológicos diferenciados, possíveis de serem identificados em suas particularidades e classificados segundo sua pertinência num território, o qual, por sua vez, adquire contornos precisos diferenciando-se como objeto daquilo que está "fora" dele.

A invenção de novas tecnologias e a especialização alcançada pela ciência ecológica irão configurar um corpo de saber ampliado, cuja finalidade é atuar sobre outros corpos fazendo existir, conduzindo ações e produzindo conceitos que alimentam a sua dinâmica técnica. Ao disciplinar a circulação de espécies e de especialistas, as áreas transformam-se em verdadeiros laboratórios de pesquisa. Trata-se de definir a natureza criando a explicação científica que a certifica e que, tornada autônoma, converte-se em medida da natureza o "objeto" cuja circulação representa o coletivo de cientistas que o havia inventado.

Tais naturezas não antecedem os procedimentos que as tornam viáveis. Não estando lá desde sempre, descobri-las é tanto criá-las quanto torná-las efetivas, isto é, sua potência enquanto invenção científica traduz-se precisamente no interesse que são capazes de despertar em outros grupos, e sua duração está associada à possibilidade de ser compartilhada por diferentes indivíduos e coleti- 
vos, construindo outros domínios, produzindo outras tecnologias. ${ }^{8}$

É a partir da criação de uma legislação específica que a operação sobre o lugar passa a ser definida, pela primeira vez, como estratégia na qual a duração não é mais garantida pela "arte" de inventar novas combinações sempre móveis de elementos. Estabelecida pela lei - que não move e nem faz mover; mas ao contrário fixa uma conduta -, a definição das áreas torna-se independente das variações dos elementos na série, pois é a lei que garante a repetição sempre idêntica do primeiro movimento.

No entanto, não é a lei que determina a criação das Unidades de Conservação, ao contrário, ela emerge com elas constituindo um território que é o seu modo de existir, de tal maneira que o ato que configura a lei e o ato de se conformar a ela são um só ato sempre em vias de se fazer. ${ }^{9}$ Cada unidade criada atualiza a primeira área e virtualiza o embate de forças entre os diferentes indivíduos e coletivos. Nada mais flutua nas séries: o que está dentro de uma área está lá desde sempre e para sempre (formas "naturais" de existência); o que está fora jamais esteve dentro e jamais estará (modos "humanos" de existência); e o que intermedeia esses mundos, falando por eles ou fazendo-os falar, são os cientistas, as instituições de pesquisa e as leis.

Dessa forma, as instituições passam a funcionar dentro da rede como fatores de integração, como práticas capazes de fixar as relações repetindo-as de modo idêntico. A lei torna possível a hierarquização de práticas que até então se colocavam exclusivamente como procedimentos diferenciados não-localizáveis, já que estavam sempre em movimento, tornando possível a normalização daquilo que seja "a natureza".

Com as Unidades de Conservação, opera-se sobre um lugar onde o marco estabelecido é traduzido como exploração e não como proteção ou conservação. Ou melhor, a proteção e a conservação são articuladas com a experiência da exploração, dando-lhes um significado no domínio de conhecimento em que emergem e na experiência que as configura. A especificidade de cada Unidade de Conservação, entendida aqui sempre como operadora, se dá a partir da definição, dentro de um universo limitado de possíveis, daquelas operações que serão realizadas sobre o lugar, onde a exploração surge como o marco para o qual todas as operações irão remeter. Distinguem-se aí diferentes fazeres, ou os diferentes fazeres da "exploração", qualificando-os a partir do grau de valor que são capazes de gerar e da quantidade de riqueza que são ca- pazes de produzir, isto é, a partir das tecnologias que são inventadas. ${ }^{10}$

É nesse processo de distinção que vão sendo articulados os diversos elementos produzidos na interação com uma natureza que vai sendo configurada. É na criação do lugar que a natureza é inventada, e na articulação entre os vários e diferentes elementos que a área adquire sua especificidade, ao mesmo tempo em que concretiza uma forma de relação entre os indivíduos e um mundo que se manifesta nesta relação.

O que está em jogo não é a ocupação do espaço mas a transformação do espaço em lugar propriamente humano. Tal definição - do que é propriamente humano - cabe simultaneamente à ciência e ao Estado, que irão dispor sobre a humanidade dos coletivos pela sua associação com certas espécies de plantas, certas práticas, e com as formas utilizadas na sua produção e consumo.

Nessa medida a conservação foi concebida não como diferenciada do uso, mas como um diferencial de uso a partir de onde se podia qualificar alguns usos enquanto depredação e outros como produção de saber, de bens de exportação ou de vida. De qualquer forma, em ambos os casos, a exploração é o marco para o qual todas as práticas eram remetidas.

A potência de um lugar reside justamente na quantidade de elementos que ele articula (indivíduos e coletivos humanos e não-humanos) e na duração desta articulação (traduzida como tornar válida a explicação que ela encerra pelo compartilhamento entre diferentes indivíduos e coletivos). A intensidade presente na duração define como a série de elementos articulados se comportam, ao mesmo tempo em que a atividade dos elementos na série define a variação da duração. Co-dependentes, são ao mesmo tempo a ação e aquilo que as constitui. É nesse movimento de trocas recursivas - que sempre se repetem - que a natureza, aquele que a descreve e sua descrição são configurados, e o que é posto em jogo não é nunca a solução do problema mas uma problematização a propósito da rede de interação que se expressa no esforço constante de conservação das relações que a compõem.

\section{PARQUES NACIONAIS E O “MODELO" DE YELLOWSTONE}

Até os anos 50, a única similaridade entre o Parque Nacional de Yellowstone e todos os parques criados na Ásia, na África e na América do Sul não ia além da nomenclatura. Yellowstone e tantos outros parques não foram criados 
nem a partir de, nem segundo modelo algum, ao contrário, cada um deles era a matriz fixa e integrada, co-determinada pelo cruzamento entre diferentes domínios de conhecimento. A potência do modelo, de qualquer modelo científico, é justamente a de articular todas as matrizes formalizando-as, tornando possível localizar, em cada parque criado, o início de uma consciência ecológica, de um reconhecimento explícito da necessidade de proteger a natureza ou, então, outro caminho possível, a primeira manifestação da presença de um modelo de proteção.

Assim, não há nenhuma grande ocultação ou segredo a ser descoberto, pois o modelo projeta na rede suas próprias qualidades, também tornadas autônomas, separadas dos coletivos com os quais estava articulada, incorporando as matrizes em seu campo de força, dando a elas sua própria origem, nomeando-as como o princípio, e esses são os artifícios que permitem criar uma temporalidade transversal às redes de interação onde cada matriz foi disposta.

O reconhecimento das Unidades de Conservação como o conjunto de operações "próprias" da ecologia aplicada irá gerar uma metamorfose em que a articulação temporal dos lugares, das Áreas Protegidas, com a rede de interações na qual é configurada, é substituída pela fundação de um lugar autônomo cuja existência se dá independentemente da variabilidade da rede de interações com a qual emerge (Certeau, 1996:97-116).

O resultado mais evidente desse processo de metamorfose é a possibilidade de vincular a existência de todas as Unidades de Conservação presentes e futuras a Yellowstone - base geradora do cálculo estratégico -, de onde se prescrevem os modos de operação e de relação que estão sempre unidos a um domínio teórico capaz de articular todo um conjunto de lugares físicos, cuja história passa a ser aquela dos grandes procedimentos tecnocientíficos: demarcar, isolar, confinar e controlar o movimento de todos os coletivos vivos, sejam eles humanos ou não-humanos.

São muitos os caminhos que levam da imensidão selvagem às Áreas Protegidas e finalmente às Unidades de Conservação. Caminhos que envolvem, sem dúvida, o aprimoramento das tecnologias científicas e políticas que permitiram ao mesmo tempo unificar naturezas singulares e territórios políticos. O trabalho necessário para a realização desse processo sempre inclui a invenção e a crença na existência de entidades singulares capazes de unificar comportamentos cabendo às leis, assim como à comunidade científica, a posição de intermediários entre essas entidades e os diferentes coletivos vivos (Latour et alii, 1998).
As Unidades de Conservação apresentam-se como o modo de operar da Ecologia sobre territórios que ela estabelece a partir da definição de seu próprio território científico, onde cada lugar, cada área, é reportada a um modelo simultaneamente científico (classificação, hierarquização) e natural, pois o critério utilizado para a criação das áreas a diversidade - seria dado pela Natureza.

A solidez da articulação entre fundamentos científicos e naturais permite à ecologia a determinação de um modelo - de área, de procedimento - eficaz na manutenção de seu território de conhecimento e das relações nele estabelecidas. Dessa maneira, ela passou a ser a ciência apta a responder à questão sobre o futuro da natureza e do planeta.

A ecologia, por sua vez, ao constituir-se como um território científico, estabelece os critérios que permitem definir a natureza - o que ela é, e o que deve continuar sendo - do que nela deve ser considerado (quais relações e quais espécies a serem preservadas e de que forma), em oposição aos processos degenerativos impostos pela ação humana sobre o ambiente.

Tais percursos traduzem, simultaneamente, a busca de uma formulação teórica que envolva todo o conjunto de relações entre os diferentes coletivos vivos, bem como sua operacionalização através da criação de áreas de proteção, cabendo a elas, por sua vez, não só a preservação das espécies, mas também de toda uma rede de relações, na qual é essencial a delimitação entre o propriamente humano em oposição ao propriamente natural.

O caminho traçado pela ecologia retoma de forma digressiva a idéia de paraíso e a de degradação, esta última imposta ao homem com a perda de seu pertencimento. Nessa lógica, a criação de áreas de proteção atualiza o paraíso perdido, incluindo-o como o possível de ser realizado, que passa a ser uma tarefa menos ecológica do que filosófico-teológica e política. Permite reconectar o humano à unidade natural (Mãe-Terra), à unidade divina (Deus, o paraíso) e, ainda e principalmente, à grande unidade política, mãe metafórica: o Estado. ${ }^{11}$

A importância das áreas de proteção está menos na biodiversidade que almeja preservar, que na semelhança que procura manter e na igualdade que pretende estabelecer pela defesa da unidade original: natureza ou Estado. Na perspectiva adotada, a finalidade da ecologia, expressa nas áreas de proteção, mais que preservar o vivo pela manutenção dos contínuos biológicos, é garantir a semelhança do vivo diante do modelo que o gerou.

Não interessa à ecologia - esta que une todos os sistemas vivos a uma unidade original - aquilo que se apre- 
senta como ruído e que causa desvio no sistema natural. Tais dissonâncias devem ser obliteradas, recalcadas ou incorporadas para que o continuum biológico possa ser mantido inalterado. Para ela, cada área de proteção forma, em si mesma, uma unidade cuja distribuição racional no espaço geográfico permite a recomposição no sistema da unidade geradora: a natureza. Cada área apresenta parcialmente a natureza e a articulação de todas as áreas compõe um Sistema de Unidades que representa a totalidade da natureza. As áreas, enquanto cópias, são reinstauradas na imagem, no modelo: a Natureza. É o retorno da multiplicidade na natureza que, em seu movimento, afirma sua identidade com ela mesma.

A ecologia, portanto, mesmo quando afirma a diversidade da natureza, supõe uma única natureza, uma origem, um fundamento ou um modelo a partir do qual e para o qual cada elemento pode ser remetido, como um decalque ou prova da existência e verdade do modelo, entendido como unidade geradora. O problema, enfim, não é o tipo de modelo, mas a crença na existência de um modelo.

O aparecimento de uma ciência propriamente ecológica, no início do século XX, permitiu o predomínio da explicação científica sobre qualquer outra descrição, seja de ordem estética ou conceitual, conferindo, desta maneira, uma ênfase menor aos cenários de grande beleza, ainda que devam ser protegidos. A experiência puramente estética - em que estavam mergulhados tanto o transcendentalismo norte-americano quanto o romantismo europeu no século XIX - foi progressivamente eliminada em proveito de uma visão e metodologias pragmáticas, as quais, cada vez mais, se articularam não só à ecologia norte-americana como a todo o pensamento ecológico ocidental.

O progressivo domínio da ecologia, entendida como um braço da biologia - e de certa forma reduzida a ela forneceu uma base científica muito mais objetiva e pragmática do que a história natural, a filosofia e a arte tinham até então oferecido.

Ao transformar a natureza em algo possível de ser objetivado, e portanto explicado como natureza-função, a ciência ecológica destituiu-a, ou assim pretendeu, de seu aspecto conceitual e estético, acreditando ser possível explicá-la a partir de suas regularidades objetivas. Forjaram-se os elementos que estruturaram um edifício jurídico-legal, com o objetivo de normatizar e disciplinar as relações entre o homem e uma natureza que o "circunda", mas que não o inclui. ${ }^{12}$
As Unidades de Conservação representam o desdobramento mais elaborado e sofisticado desse saber tecnocientífico, cujo acontecimento é a afirmação da existência de uma única natureza: aquela que está destinada à preservação.

Essa concepção vem sendo progressivamente incorporada pelas ciências sociais, cujo papel tem sido o de identificar e nomear práticas humanas distintas, tornando-as visíveis e, desta forma, integrando-as ao discurso preservacionista, permitindo assim a seleção e o controle das ações humanas dentro e fora das áreas baseados no grau de "aptidão" que esses coletivos teriam para a manutenção da diversidade. ${ }^{13}$

Do ponto de vista de seu funcionamento, esse modelo gerado pela ciência ecológica e absorvido pelas ciências sociais é formado por modos de operação específicos sobre os lugares designados como áreas de proteção. $\mathrm{O}$ modelo está sempre impregnado do discurso normativo que o fixa, devendo haver uma concordância necessária entre o discurso da norma - o modelo científico, o domínio em que é gerado e a legislação que a formaliza - e as experiências descritas pelos indivíduos. Desse modo, a unificação das naturezas singulares por meio do modelo, não prescinde da unificação dos territórios através das leis.

É assim que o discurso jurídico-científico faz funcionar as relações entre todos os coletivos humanos e os não-humanos estabelecendo aquilo que é próprio de cada um e afirmando que a cada qual correspondem planos separados e opostos possíveis de serem concebidos um sem o outro. ${ }^{14}$

Em nosso modo de ver, essa é a "grande história" do modelo, de todos os modelos científicos: fazer crer que uma entidade estável e universal habita as profundezas do real, esperando vir a ser descoberta por alguns escolhidos; existe desde sempre, antes e para além de toda experiência, como medida de todas as coisas. Em suma, faz-se crer como a grande solução para os problemas, pois como uma entidade estável ela sempre se apresenta como lógica e funcional.

A grande história do modelo, e a própria idéia de modelo científico, oculta o processo de invenção envolto na criação das redes de interação. O que tal perspectiva encobre são as "pequenas" histórias, as micro-histórias, que surgem com as redes de interação e as compõem, "refazendo-as" ou simplesmente eliminando-as como resíduos, impropriedades, a cada formulação de novas regras científicas.

O modelo, supostamente estável, está ancorado em uma rede de elementos heterogêneos que mantêm a sua exis- 
tência. São coletivos de coisas, indivíduos e tecnologias, cuja articulação, sempre singular, produz efeitos sobre essa rede para que ela se encontre em permanente redefinição.

Assim, os modos de operação formados pelas Unidades de Conservação, erigidos em modelo pela ciência ecológica nos anos 50, avançam, através das leis, sobre o corpo territorial. E o que nele se inscreve é reconhecido como sendo ditado pela própria realidade. É pela encarnação no território que a lei se faz crer e o modelo emerge como algo que "sempre foi" ou que "existe desde sempre" (Certeau, 1996:241).

Integrar naturezas, unificar territórios, traduz a eficácia desse trabalho de circulação, no qual singularidades produzidas são "refeitas" e transformadas numa única experiência compartilhável por todos os coletivos e indivíduos.

Definir o que é a natureza continua sendo o problema, pois ela jamais cansa de ser outras coisas, outras relações que escapam por entre a explicação científica. Se ela já não é mais as séries articuladas ou as medidas de proporção, também já não é a genealogia ou a filiação e passa a ser as populações que variam de um meio a outro ou num mesmo meio. Se o homem era antes o termo eminente da série, ele passa a ser um elemento inexorável do sistema, uma ligação num circuito extenso ou um fator de desequilíbrio na dinâmica de processos físicos e bioquímicos.

Portanto, a capacidade de gerar os fenômenos que a explicação científica propõe - o isomorfismo de qualquer modelo científico -, interessa-nos menos que o fato de o âmbito, onde emerge o modelo, não existir independentemente daquele(s) que o cria(m) e dos espaços relacionais nos quais "o criador" se realiza.

Esse caminho nos permite afirmar que os biólogos e/ ou ecólogos constroem o seu contexto (a biologia da conservação) ao criar o modelo de Unidades de Conservação, que por sua vez especifica o seu domínio de validade ao mesmo tempo que estabelece quais as observações possíveis de serem feitas dentro dele. Se esse é o processo que define o domínio de referências em que o modelo é válido, nenhum dos elementos nele articulado - ou sua forma de articulação - pode ser dado de antemão ou considerado como absoluto ou universalmente válido.

De fato, tais ligações são tão contingentes e tão provisórias quanto as explicações científicas que as estabelecem, e o limite do modelo é dado justamente pelos elementos que ele é capaz de relacionar. Por outro lado, o modelo de Unidades de Conservação certifica a explicação científica que o cria, estabelecendo o fato científico de sua criação (a biodiversidade) como a medida comum entre o mecanismo que a gera (o modelo de unidades de conservação) e o interesse dos biólogos, dos ecólogos, e de quantos coletivos tal medida puder articular.

É somente ao considerar o modelo como co-dependente de quem o cria e das tecnologias que o possibilitam, que se pode compreender o processo que - ao produzir os fatos e o sistema de interação no qual eles emergem -, estabelece um domínio para além do qual não só sua validade não é reconhecida como ele deixa de ser a medida da verdade da explicação científica que o constrói. ${ }^{15}$

É a apresentação da natureza como totalidade real e objetiva que se afirma na própria criação das unidades de conservação, constituindo-as como parte fundamental de uma "estratégia de conservação", sobretudo porque elas testemunham a fragmentação do território político, dos ecossistemas, como um erro a ser corrigido.

As Unidades de Conservação são apresentações atuais da ciência como uma promessa de redenção possível. Afirmam a existência de uma única natureza: aquela que deve ser protegida; um real: aquele que fornece os fatos que sustentam a explicação científica; um mundo: formado pela identidade com essa promessa. Elas estabelecem assim uma natureza genérica contraposta a indivíduos genéricos que, separados das condições que os suportam, tornam-se "idéias", objetos da explicação científica, a qual procura, para além deles, uma verdade, a única verdade, remetendo-os a um mundo, a uma natureza, de onde seriam originários.

Considerar a natureza como a Natureza é se conformar, no sentido mais forte deste termo, à integração máxima de todos os coletivos, reconhecer o modelo como o seu "tradutor", considerando-o como algo descolado do ato de compor uma natureza, uma cultura, uma tradição. Existem os modelos, sua grande história, mas existem também suas derivas. Segui-las é seguir as micro-histórias, aquelas que jamais seguem os modelos.

\section{NOTAS}

E-mail da autora: heep@ig.com.br

Este artigo é resultante da dissertação de mestrado da autora (Godoy, 1999).

1. A Renascença americana corresponde ao período do Romantismo norte-americano, cujos fundamentos foram dados pelo transcendentalismo emersoniano, manifestando-se na literatura, na pintura, na fotografia, na filosofia e nas ciências. O que estava implicado nesse movimento era a certeza de que a natureza era um texto sagrado que se oferecia a interpretação. A potência da relação entre Deus e a Natureza evidencia-se pelas reflexões de Ralph Waldo Emerson, para quem a natureza é um agente onipotente "em torno do qual todos os atos humanos tornam-se satélites". Nesse sentido, a arte deve ser um complemento da 
natureza e o trabalho do artista a sua tradução fiel: ele não faz o que quer mas o que precisa ser feito. Emerson (1965) afirma que a natureza pinta a melhor parte dos quadros; esculpe a melhor parte das estátuas; constrói a melhor parte das casas; escreve a melhor parte dos poemas e fala a melhor parte das orações, porque ela é a lei e é dela a força dos atos humanos, porque a natureza é a mente universal: Deus.

A idéia de que na natureza estão inscritos os divinos propósitos, que nela está o destino manifesto e que, a pintura, a poesia e a fotografia, assim como a filosofia e a ciência, traduzem estes desígnios, fazia ecoar a concepção de Unidade - em Deus e na Nação, no indivíduo e no espaço geográfico -, de tal forma que o conceito de natureza e a idéia de um "caráter norte-americano" tornavam-se complementares. Essas questões foram abordadas em profundidade em Godoy (1999).

2. Em Olmstead (1998) encontramos o seguinte parágrafo: "The union of the deepest sublimity with the deepest beauty of nature, not in one feature or another, not in one part or one scene or another, not any landscape than can be framed by itself, but all around and wherever the visitor goes, constitutes the Yo Semite the greatest glory of nature." Numa tradução livre: "A união da mais profunda grandiosidade com a mais profunda beleza da natureza, não em um aspecto ou em outro, não em uma parte da cena ou em outra, nem nenhuma paisagem que possa ser enquadrada por ela mesma, mas em todo o entorno e para onde quer que o visitante vá, constitui o Yo Semite como a maior glória da natureza."

3. "Nature and Man shall be disjoin'd and diffused no more,/ The true Son of God shall absolutely fuse them". A noção de cultivar, tal como é expressa por Emerson (1950) implica que ao revolver a terra, tomando-a como parte de um desígnio, o homem transformaria o inculto (disforme) em culto (forma). Cultivar é nesse sentido criar a cultura (a forma) a partir da natureza, modelando-a segundo o que havia sido determinado pela Providência.

4. A partir de 1870 articula-se, em torno da figura de Chauncey Wright, um grupo de filósofos conhecido como Clube Metafísico. Chauncey será o primeiro a defender uma filosofia cujos fundamentos não estavam nem na religião, como em Edwards, nem na intuição, como em Emerson, mas numa consideração desapaixonada e imparcial dos fatos. Dessa forma, assim como na ciência, as idéias filosóficas deveriam estar sujeitas a verificação objetiva. As idéias de Chauncey buscavam uma articulação, até então inédita, entre a teoria evolucionista proposta por Darwin, quem conhecera em 1872, e a filosofia; propondo, assim, uma filosofia científica (ou positivista) que teve um grande impacto sobre os filósofos subseqüentes. Abre-se o caminho para o chamado realismo pragmático (de Peirce, James e Dewey) e para o idealismo pragmático (de Royce e Santayanna). A esse respeito ver Sthro (1968).

5. Em Langdorf (1872) encontra-se a seguinte orientação a respeito dos objetivos de Yellowstone: "It is not the desire of the Department that any attempt shall be made to beautify or adorn this reservation, but merely to preserve from injury or spolation the timber, mineral deposits, and various curiosities of that region, so far as possible, in their natural condition."

6. O Homestead Act criado em 1864 dá início a expansão legal da fronteira norteamericana em direção ao Oeste. A partir de 1874, ano da criação de Yellowstone, os grupos de pesquisa geológica - financiados pelo Estado - começam a sinalizar a falta de áreas agricultáveis, principalmente a nordeste. A partir de então desencadeia-se um conflito, com fortes colorações lobistas, entre os grupos ligados à pesquisa geológica, e aqueles com interesses na área, como os representantes da Transcontinental. Como coloca Smith (1978), apelava-se pela primeira vez a uma reformulação do programa de terras a partir de critérios racionais e científicos e não meramente especulativos.

7. Inventar a América, como afirma Emerson (1997:140), é realizar uma "conversão", um giro sobre os próprios passos, reverter a direção, caminhar em direção a ela, a sua verdadeira substância, é morrer para renascer nesta nova América ainda inabordável que Emerson encontrou no Oeste. Trata-se, como coloca Thoreau, de "repovoar os bosques". Repovoar a América é tanto tarefa da literatura, quanto da filosofia e da ciência.

8. Até meados do século XX, os critérios utilizados para a criação de Áreas Protegidas pouco tinham a ver com os conceitos desenvolvidos pela ecologia, embora tais áreas pudessem fazer ecoar os conceitos criados por ela. Foi preciso ligar a ecologia a outras ciências, criando outros conceitos, para que essas áreas pudessem ser articuladas de forma que cada uma passasse a ser um componente estrutural de um sistema cuja articulação, em termos práticos, estivesse sempre remetida a uma totalidade teórico-conceitual. Tal foi o efeito do conceito de ecossistema, tal é o efeito do conceito de biosfera. O conceito de ecossistema é definido por Arthur Tansley (The use and abuse of vegetational concepts and terms. Apud Deléage, 1993), que insiste fortemente no fato de que os ecossistemas não são dados brutos da natureza, mas o produto de uma criação mental que permite isolá-los, imaginando uma fronteira entre eles e o resto do universo. Já o conceito de biosfera, foi definido por Vernadsky nos anos 20 o qual dedicou-lhe um livro, La Biosphère em 1926. Essa noção corresponde a uma conceitualização da vida terrestre concebida como uma totalidade. Já as primeiras tentativas aprofundadas de quantificação e de modelização matemática da dinâmica das comunidades de seres vivos irão concretizar-se no decorrer dos anos $20 \mathrm{com}$ os físico-matemáticos Alfred J. Lotka e Vito Volterra (Deléage, 1993:102-103 e 170186).

9. Essa discussão, em seus aspectos mais teóricos, é aprofundada por Eirado e Passos (1997).

10. O termo tecnologia é empregado aqui na acepção de François Laruelle, isto é, sendo simultaneamente a coisa (a força, a maquinaria, o material) e o saber da coisa. O que importa são as combinações que se efetivam. Tal conceito é apresentado em Laruelle (1998).

11. A idéia de conexão pode ser muito bem descrita pelo termo "pertencimento" da forma como Peter Sloterdijk utiliza-o: "como sinônimo de conservação das chances de vida" (Sloterdijk, 1999:74).

12. A descrição de uma natureza exterior ao coletivo humano não se dá, evidentemente, com o surgimento da ecologia. No entanto, é a partir dela, e mais especificamente a partir da ecologia aplicada, que passa a ser possível estabelecer áreas de proteção como sendo o lugar da natureza e não do homem. Tal separação implica uma separação entre o universo das ciências e dos coletivos, opondo planos que embora distintos não podem ser concebidos um sem o outro. Essa discussão e suas implicações são aprofundadas por Latour et alii (1998).

13. O problema dessa argumentação é que permanece presa aos referenciais utilizados pela biologia da conservação só que ancorados nos coletivos humanos em vez de não-humanos. Nesse sentido, tanto as ciências sociais quanto a ecologia afirmam a possibilidade de um argumento objetivo, dado pela experiência, remetendo-se sempre a um real ou a uma natureza que é representativamente racional, inegável e portanto universalmente válida. Como coloca Maturana et alii (1998), "este caminho implica que toda proposição explicativa encontrará sua validade, explícita ou implicitamente, em categorias últimas de validade, universais ou transcendentes, tais como a Realidade ou o Real, a Natureza, a Matéria, a Energia, a Consciência ou a Humanidade".

14. O modelo científico que a biologia da conservação e a ecologia de modo geral se utilizam está baseado em formulações matemáticas, o que implica na recusa de qualquer formulação, na esfera da lógica expressa pela figura do paradoxo que fere o postulado, segundo o qual as afirmações sobre algo não devem ser elementos constituintes deste algo. Assim, os coletivos humanos só podem ser considerados se permanecerem separados da natureza. Sua inclusão pressupõe aceitação do paradoxo e, portanto, a aceitação da existência de algo puramente indeterminado. Para aprofundar mais essa discussão sugerimos ver Eirado e Passos (1997), e Maturana e Varela (1997).

15. Para um maior aprofundamento das questões relativas à ciência e aos domínios explicativos que ela gera, sugerimos a leitura de Maturana et alii (1998); Stengers (1989); e Latour (1987 e 1998).

\section{REFERÊNCIAS BIBLIOGRÁFICAS}

CERTEAU, M. A invenção do cotidiano. Petrópolis, Vozes, 1996.

DELÉAGE, J.P. História da ecologia: uma ciência do homem e da natureza. Lisboa, Pub. Dom Quixote, 1993.

EIRADO, E. e PASSOS, A. Notas sobre a relação entre autonomia e virtualidade. Simpósio Internacional sobre autopoiesis. Belo Horizonte, 1997.

EMERSON, R.W. "Experiência”. In: Stanley Cavell. Esta América nova, ainda inabordável. São Paulo, Ed.34, 1997.

"Nature." In: ATKINSON, BROOKS (ed.). The complete essays and others writings of Ralph Waldo Emerson. Nova York, The Modern Library, 1950.

"Thoughts on art". In: MCCOURBREY, J.W. American art: 17001960 (source and documents). Nova Jersey, Prentice Hall, 1965.

GODOY, A. "Da imensidão selvagem às áreas protegidas: inventando naturezas, criando lugares”. Dissertação de mestrado. São Paulo, PUC, jun. 1999.

LANGDORF, N. P. "Letter from the Secretary of the Interior". Library of Congress, 1998, originalmente apresentado na 42d Congress, 3d session, 1872 (www.lcweb.loc.gov). 
LARUELLE, F. "Para o conceito de "não-tecnologia"”. In: ARAUJO, H. (org.). Tecnociência e cultura. São Paulo, Estação Liberdade, 1998.

LATOUR, B. Science and action. Londres, Un. Press, 1987.

LATOUR, B. et alii "Crise do meio ambiente: desafios às ciências humanas". In: ARAUJO, H. (org.). Tecnociência e cultura. São Paulo, Estação Liberdade, 1998.

MATURANA, H.; MAGRO, C.; GRACIANO, M. e VAZ, N. (orgs.). A ontologia da realidade. Belo Horizonte, UFMG, 1998.

MATURANA, H. e VARELA, F. De máquinas e seres vivos: autopoiese - a organização do vivo. Porto Alegre, Artes Médicas, 1997.
OLMESTEAD, F.L. "Draft of preliminary repport upon the Yosemite and the big tree grove". Frederick Law Olmestead Papers, Manuscript Division, Library of Congress, 1998, publicado originalmente por United States Sanitary Comission, 1864 (www.lcweb.loc.gov).

SLOTERDIJK, P. No mesmo barco - Ensaios sobre a hiperpolítica. São Paulo, Estação Liberdade, 1999.

SMITH, H.N. Virgin Land: the american west as symbol and myth. Mass., Harvard; Un. Press, 1978.

STENGERS, I. Quem tem medo da ciência. São Paulo, Siciliano, 1989.

STHRO, G. A filosofia norte-americana. São Paulo, Cultrix, 1968. 